\title{
Spectrophotometric Determination of Trace Amounts of Mercury With Phenanthroline and Eosin
}

\author{
Jayateerth R. Mudakavi \\ Department of Chemical Engineering, Indian Institute of Science, Bangalore-560012, India
}

\begin{abstract}
A sensitive method has been developed for the determination of mercury $10.2-1.2$ p.p.m.) using phenanthroline and eosin in an aqueous medium. The reaction occurs at $\mathrm{pH} 4.5$. Various metal ion interferences have been evaluated.
\end{abstract}

Keywords: Mercury(II) determination; spectrophotometry; phenanthroline; eosin

Owing to the toxicity of mercury in the environment, the determination of trace amounts of mercury has attracted great attention. 1,2 The conventional technique of dithizone extraction is not always favoured because the procedure is cumbersome, sensitive to light and is subject to interferences from other metal ions. ${ }^{3}$ Analytical methods based on ternary complex formation seem to offer superior sensitivity and selectivity. A number of ternary systems $s^{4-7}$ have been proposed for the determination of mercury, among which the tetrabromomercurate(II) - methylene blue system is the most sensitive. However, most of the ternary systems involve an additional extraction step. Colour development and measurement in aqueous solution itself would alleviate this difficulty, leading to a rapid, more accurate and precise analytical method.

A survey of the various ternary systems proposed for mercury revealed that anionic mercury complexes are coupled with cationic dyes to form the ternary complex. On the other hand, the reaction of mercury with neutral ligands and anionic dyes can be utilised to form ternary complexes.

A detailed examination of the reaction of mercury with phenanthroline-type compounds and anionic dyes showed that the colour reaction of mercury, phenanthroline and eosin could be used to advantage with an aqueous finish. This paper describes studies conducted on this system.

\section{Experimental}

\section{Apparatus}

A Shimadzu Graphicord UV-240 spectrophotometer with $10-\mathrm{mm}$ matched quartz cells and a Toshniwal $\mathrm{pH}$ meter with a combined glass electrode was used.

\section{Reagents}

All reagents were of analytical-reagent grade unless stated otherwise

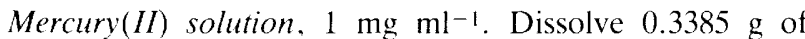
mercury(II) chloride in water and dilute to $250 \mathrm{ml}$. Dilute an appropriate volume of this solution to provide a 10 p.p.m. solution of mercury(II).

Phenanthroline solution, $0.05 \%$. Dissolve $0.05 \mathrm{~g}$ of 1,10 phenanthroline monohydrate in $100 \mathrm{ml}$ of water. Store in an amber-coloured bottle.

Acetate buffer, $p H 4.5$. Mix $124 \mathrm{ml}$ of $1 \mathrm{~N}$ acetic acid with 50 $\mathrm{ml}$ of $1 \mathrm{~N}$ sodium hydroxide solution and dilute to $500 \mathrm{ml}$ with distilled water. Adjust the final $\mathrm{pH}$ of the solution to 4.50 .

Eosin solution, $0.05 \%$. Dissolve $0.125 \mathrm{~g}$ of eosin (C.I. 45380 ) in water and dilute to $250 \mathrm{ml}$.

EDTA solution, $0.05 \mathrm{~m}$. Dissolve $1.8615 \mathrm{~g}$ of EDTA in 100 $\mathrm{ml}$ of distilled water.

Gelatine solution, $0.05 \%$. Dissolve $0.025 \mathrm{~g}$ of gelatine in $50 \mathrm{ml}$ of hot water. Prepare fresh daily.

\section{Procedure}

To a series of solutions containing 5-30 $\mu \mathrm{g}$ of mercury(II) add $1.0 \mathrm{ml}$ of $0.05 \mathrm{~m}$ EDT A solution, $5 \mathrm{ml}$ of $\mathrm{pH} 4.5$ buffer, $2 \mathrm{ml}$ of $0.05 \% 1,10$-phenanthroline solution and $1 \mathrm{ml}$ of $0.05 \%$ gelatine solution. Mix the contents well and add $5 \mathrm{ml}$ of $0.05 \%$ eosin solution. Again mix the solutions and dilute to $25 \mathrm{ml}$. Measure the absorbance of the samples in $10-\mathrm{mm}$ cells at 552 $\mathrm{nm}$ against a reagent blank. Prepare a calibration graph for 5-30 $\mathrm{gg}$ of mercury.

Develop the colour similarly for the unknown and determine its concentration by refering to the calibration graph.

\section{Results and Discussion}

Preliminary studies of the reaction of mercury, 1,10phenanthroline and eosin indicated that the reaction proceeded immediately after mixing the reagents. However. owing to the colloidal nature of the products, precipitation from both the sample and the reagent blank occurred on standing. Addition of poly(vinyl alcohol) or sodium carboxymethylcellulose stabilised the colour system, but under these conditions the absorbance decreased slowly over a period of time. Gelatine, on the other hand, solubilised the precipitate and allowed the absorbance to remain constant for more than $6 \mathrm{~h}$. To avoid the precipitation, therefore, gelatine was added before the addition of eosin.

Fig. 1 shows the absorption spectra of varying concentrations of the mercury - 1,10-phenanthroline - eosin complex at $\mathrm{pH}$ 4.5. The interaction between mercury and the reagents proceeds with a bathochromic shift. The complex showed an absorption maximum at $550 \mathrm{~nm}$ and the maximum absorbance difference between the complex and the reagent was at $552 \mathrm{~nm}$.

\section{Effect of Experimental Variables}

The optimum $\mathrm{pH}$ for the reaction was examined over the $\mathrm{pH}$ range 1.0-8.0. To a series of solutions containing $25 \mu \mathrm{g}$ of mercury(II) solution in $25-\mathrm{ml}$ beakers, $1 \mathrm{ml}$ of $0.05 \mathrm{M}$ EDTA solution, $2 \mathrm{ml}$ of $0.05 \% 1,10$-phenanthroline solution, $1 \mathrm{ml}$ of $0.05 \%$ gelatine solution and $5 \mathrm{ml}$ of $0.05 \%$ eosin solution were added and the $\mathrm{pH}$ was adjusted to cover the range $1.0-8.0$ using dilute hydrochloric acid or sodium hydroxide solution and a $\mathrm{pH}$ meter. The absorbances of these solutions, diluted to $25 \mathrm{ml}$, were measured against blanks at $552 \mathrm{~nm}$. Fig. 2 shows that maximum complex formation occurs over the $\mathrm{pH}$ range 4.3-4.7 As the absorbance of the reagent blank also varies with $\mathrm{pH}$ (Fig. 3), it is necessary that the $\mathrm{pH}$ of the sample and reference should be very close. A pH of 4.50 was maintained in all subsequent investigations, by using an acetate buffer of $0.1 \mathrm{~m}$ concentration. As the reaction was unaffected in the presence of EDTA, it was decided to add $1.0 \mathrm{ml}$ of $0.05 \mathrm{M}$ EDTA solution to all samples to suppress the interferences of any other foreign metal ions. 


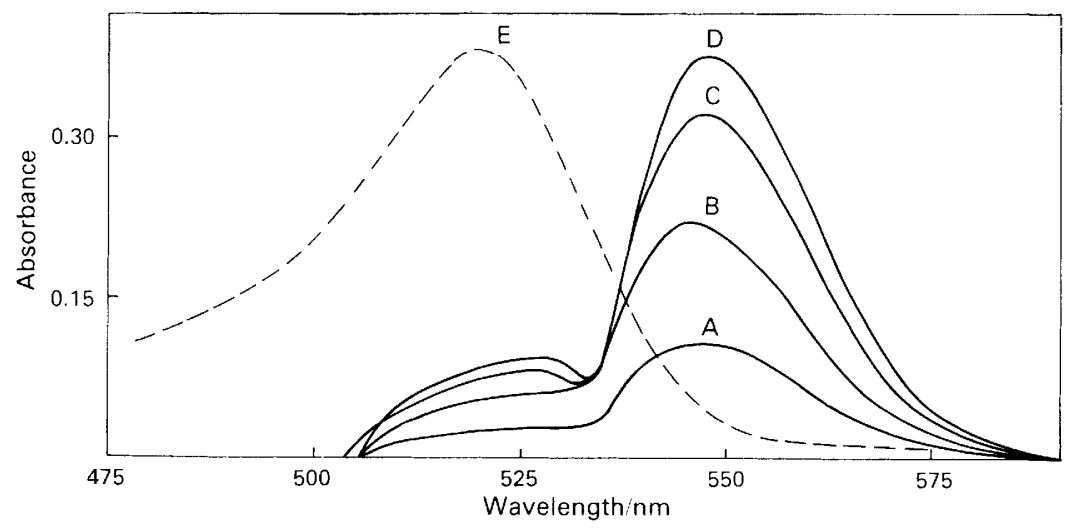

Fig. 1. Absorption spectra of $\mathrm{Hg}(\mathrm{II})$ complexes for varying concentrations of $\mathrm{Hg}(\mathrm{II})$. $\mathrm{A}: \mathrm{Hg}(\mathrm{II}), 5 \mu \mathrm{g}$; EDTA solution, 1 ml; 1,10-phenanthroline solution, $2 \mathrm{ml}$; gelatine solution, $1 \mathrm{ml}$; buffer solution, $5 \mathrm{ml}$; and eosin solution. $5 \mathrm{ml}$ in $25 \mathrm{ml} ; 10-\mathrm{mm}$ cells. $\mathrm{B}-\mathrm{D}$, as $\mathrm{A}$ but with 15,20 and $25 \mu \mathrm{g}$ of $\mathrm{Hg}(\mathrm{II})$, respectively

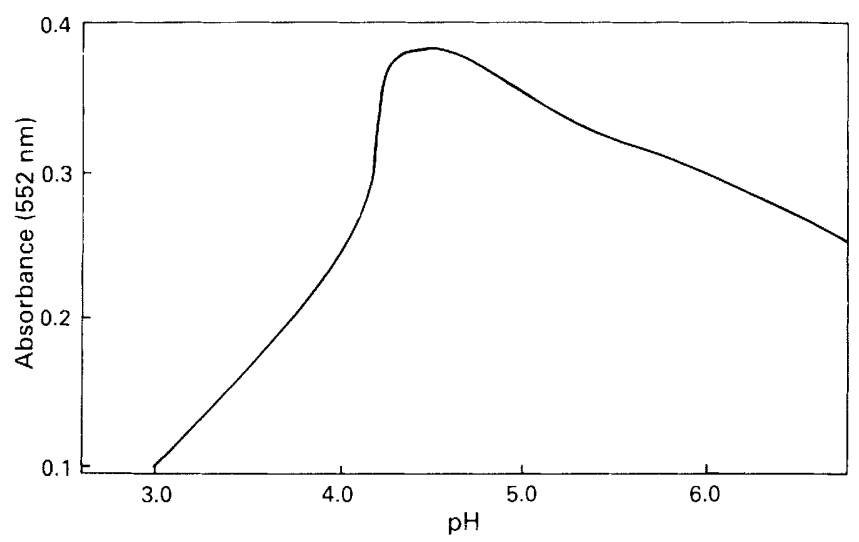

Fig. 2. Effect of $\mathrm{pH}$ on absorbance. Conditions: $\mathrm{Hg}(\mathrm{II}), 25 \mu \mathrm{g}$; EDTA solution, $2 \mathrm{ml} ; 1,10$-phenanthroline solution, $1 \mathrm{ml}$; gelatine solution, $1 \mathrm{ml}$; buffer solution, $5 \mathrm{ml}$; and eosin solution, $5 \mathrm{ml}$ in $25 \mathrm{ml}$; $10-\mathrm{mm}$ cells

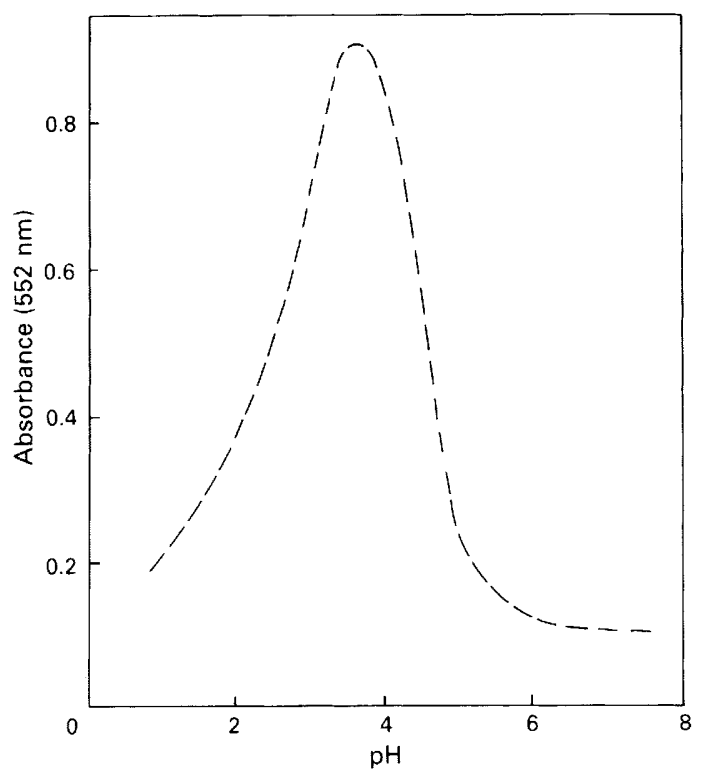

Fig. 3. Variation of absorbance of reagent blank with $\mathrm{pH}$. Condi. tions as in Fig. 2, except no $\mathrm{Hg}$ (II) and using 5-mm cells
The influence of 1,10-phenanthroline was investigated next. To a series of solutions containing $25 \mu \mathrm{g}$ of mercury(II), $5 \mathrm{ml}$ of $\mathrm{pH} 4.5$ acetate buffer, $1 \mathrm{ml}$ of $0.05 \mathrm{~m}$ EDTA solution and varying volumes of $0.05 \% 1,10$-phenanthroline solution were added. Colour development was completed by adding $1 \mathrm{ml}$ of $0.05 \%$ gelatine solution and $5 \mathrm{ml}$ of $0.05 \%$ eosin solution and diluting to $25 \mathrm{ml}$. When the volume of 1,10 -phenanthroline solution added was $2 \mathrm{ml}$ or greater, the absorbance attained a constant maximum value. However, at volumes greater than 2 $\mathrm{ml}$, a tendency for precipitation to occur was shown by the blank. A volume of $2 \mathrm{ml}$ was therefore considered to be optimal and was maintained in subsequent investigations.

To determine the effect of eosin, a similar experiment was carried out by varying the dye concentration. The absorbance of the complex reached a maximum at $3.5 \mathrm{ml}$ of $0.05 \%$ eosin solution and remained constant when larger volumes were used. A volume of $5 \mathrm{ml}$ of the dye was added in all further experiments.

The order of addition was not critical except that when the gelatine was added after the reagents the reproducibility became poor. Therefore, in subsequent work the gelatine was added before introducing the dye solution.

\section{Beer's Law and Precision}

Beer's law was obeyed over the range 5-30 $\mu \mathrm{g}$ of mercury in a final volume of $25 \mathrm{ml}$. Under the conditions described the molar absorptivity was $8.0 \times 10^{4} \mathrm{I} \mathrm{mol}^{-1} \mathrm{~cm}^{-1}$ for mercury. The Sandell sensitivity corresponding to 0.001 absorbance was $6 \mathrm{ng} \mathrm{cm}^{-2}$. The relative standard deviation for ten determinations of $25 \mu \mathrm{g}$ of mercury was $0.053 \%$.

\section{Nature of the Complex}

Phenanthroline coordinates readily with mercury(II) to form mono, bis and tris complexes. Bisphenanthroline - mercury(II) complexes of the type $\mathrm{HgX}_{2} \mathrm{~B}_{2}$ precipitate on mixing ethanolic solutions of phenanthroline and mercury(II) halide. ${ }^{8} \mathrm{~A}$ trisphenanthroline - mercury(II) complex has been isolated as the perchlorate salt from aqueous solution. ${ }^{9}$ Under the experimental conditions, as an excess of 1,10phenanthroline is present only bis and tris complexes are expected to be predominant. Further, addition of perchlorate salt did not precipitate the complex but an ethanolic solution of 1,10-phenanthroline did precipitate the mercury, indicating that the experimental conditions are favourable for the formation of the bis complex, ${ }^{10}$ viz., $\mathrm{HgCl}_{2}(o \text {-phen })_{2}, \log \beta_{2}$ $=19.65$.

The ratio of eosin to mercury was determined to be $1: 1$ by the molar ratio and Job's continuous variations methods. 
Hence the complex appears to have empirical composition $\left[\mathrm{Hg}(o \text {-phen })_{2}\right] \mathrm{R}$, where $\mathrm{R}$ represents a divalent eosin anion. This stoicheiometry was further confirmed by employing Adron s" modified procedure, with which he showed that for any two reacting species $\mathrm{A}$ and $\mathrm{B}$ forming a coloured product $A_{1} B_{1}$ the plot of $1 /$ absorbance versus $1 /$ reagent concentration would be a straight line, provided that reagent concentration is high. In the present work the graph of 1/absorbance versus $1 /[$ eosin] was linear and the apparent formation constant of the complex was calculated to be $4.7 \times 10^{3}$, which shows that the complex is weak and that a large excess of reagent is necessary for the reaction to go to completion.

\section{Interference of Foreign Ions}

The interference of various ions in the determination of $25 \mu \mathrm{g}$ of mercury was determined by carrying out the reaction according to the recommended procedure in the presence of $1.0 \mathrm{mg}$ of the desired metal ion. The results are summarised in Table 1.

Among the anions, thiocyanate and cyanide interfered seriously. The interference of $\mathrm{Al}(\mathrm{III}), \mathrm{Ti}(\mathrm{IV}), \mathrm{Mn}(\mathrm{II})$ and $\mathrm{V}(\mathrm{V})$ was overcome by the addition of $1 \mathrm{ml}$ of $0.1 \mathrm{M}$ sodium

Table 1. Results of interference studies

$$
\text { Interferent }
$$

Interference

$\mathrm{Li}(\mathrm{I}), \mathrm{Ca}(\mathrm{II}), \mathrm{Sr}(\mathrm{II}), \mathrm{Ba}(\mathrm{II}), \mathrm{Mg}(\mathrm{II}), \mathrm{Be}(\mathrm{II})$, U(VI), Cr(III), Fe(III), Tl(III), La(III), Ce(IV), Zr(IV), Pt(IV), Pd(II), Se(IV), $\mathrm{Te}(\mathrm{IV}), \mathrm{As}$ (V). sulphate, sulphite, borate. fluoride, oxalate, citrate, tartrate, nitrate, chloride, bromide ... . . . . . . . . . No interference

Cyanide, thiocyanate, iodide, Mo(VI), Tl(I),

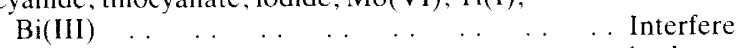
by decreasing the absorbance

$\mathrm{Mn}(\mathrm{II}), \mathrm{Al}(\mathrm{III}), \mathrm{Cr}(\mathrm{VI}), \mathrm{Pb}(\mathrm{II}), \mathrm{Zn}(\mathrm{II})$, Th(IV), Sb(V), Co(II), Ni(II), Cu(II), V(V), W(VI), Ti(IV)

Interfere by fluoride solution. The interference due to $\mathrm{Bi}(\mathrm{III}), \mathrm{Cr}$ (VI) and $\mathrm{Mo}(\mathrm{VI})$ could be removed with $1 \mathrm{ml}$ of $0.1 \mathrm{M}$ citric acid. Tungsten(VI) did not affect the determination of mercury when tartaric acid was present. Up to $100 \mu \mathrm{g}$ of $\mathrm{Cu}(\mathrm{II})$ and Co(II) could be extracted by solvent extraction with 8 -hydroxyquinoline in chloroform. The tolerance limits for other ions were $\mathrm{Zn} 20, \mathrm{Ni} 45$ and $\mathrm{Pb} 4$ p.p.m.

\section{Application of the Method}

The validity of the method was checked by analysing a factory effluent containing mercury and synthetic sea-water samples by the standard additions technique. The results shown in Table 2 are in good agreement with the expected values.

\section{Conclusions}

The proposed method is simple, sensitive and rapid. It is less laborious and less sensitive to light than the dithizone method. The few interferences encountered can be eliminated by simple masking and extraction techniques.

\section{References}

1. Ure, A. M., Anal. Chim. Acta, 1975, 76, 1

2. Chilov, S., Talanta, 1975, 22, 206.

3. Sandell, E. B., "Colorimetric Methods of Analysis," Interscience, 1959 , p. 445.

4. Lebedeva, S. P. A., Arm. Khim. Zh., 1975, 25, 303.

5. Tanaka, T., Chem. Pharm. Bull., 1978, 26, 3139

6. Shestidesyatnya, N. L., Voronich, O. G., and Motyl, V. A., Zh. Anal. Chim., 1977, 32, 260.

7. Kovalenko, A. A., Uvaroa, K. A., Usatenko, Yu. I., and Zubtsova, T. I., Zh. Anal. Khim., 1977, 32, 270 ,

8. Sutton, G. J., Aust. J. Chem., 1952, 12, 637.

9. Schilt, A. A., and Taylor, R. C., J. Inorg. Nucl. Chem., 1958, 9, 211.

10. Anderegg, G., Helv. Chim. Acta, 1963, 46, 2397

11. Adron, M., J. Chem. Soc., 1957, 1811.

Paper A3/184

increasing the absorbance

Table 2. Determination of mercury in a factory effluent and in synthetic sea water

\begin{tabular}{ccc}
\multicolumn{3}{c}{ Effluent } \\
\hline Added $/ \mu \mathrm{g}$ & Found $/ \mu \mathrm{g}$ & Recovery, \% \\
0 & 7.5 & - \\
5 & 12.0 & 96 \\
10 & 16.5 & 95 \\
15 & 23.0 & 102
\end{tabular}

\begin{tabular}{ccc}
\multicolumn{3}{c}{ Synthetic sea water } \\
\hline Added $/ \mu \mathrm{g}$ & Found $/ \mu \mathrm{g}$ & Recovery, \% \\
0 & 0 & - \\
10 & 9.4 & 94 \\
15 & 14.5 & 97 \\
30 & 29.2 & 97
\end{tabular}

